\author{
Cadernos de \\ ESTUDOS LINGUÚSTICOS - (59.1), Campinas, pp. $73-89$ - jan./abr. 2017
}

\title{
INTEGRAÇÃO EXPERIENCIAL E DÊIXIS LOCATIVA: O PAPEL DISCURSIVO DOS GESTOS
}

\author{
MAÍRA AVELAR* \\ LILIAN FERRARI**
}

\begin{abstract}
RESUMO: Este trabalho enfoca os dêiticos locativos 'aqui' e 'lá' no discurso político, a partir de dados vídeogravados do português brasileiro. Com base no arcabouço teórico da Linguística Cognitiva, a análise conjuga construtos associados à Teoria dos Espaços Mentais e à Gramática Cognitiva, retomando a noção de Integração Conceptual (FAUCONNIER \& TURNER, 2002), e a noção a ela relacionada de Integração Experiencial (AUCHLIN, 2013), bem como a operação de construal, a partir de um de seus desdobramentos em termos do conceito de focalização, baseado na dicotomia figurafundo (LANGACKER, 1991, 2008, 2013). Com o objetivo de caracterizar o significado emergente no espaço-mescla, investiga-se a articulação entre usos dos dêiticos 'aqui' e 'lá' e configurações gestuais concomitantes. Os resultados da análise evidenciam que usos discursivos desses dêiticos emergem da integração entre um espaço de input conceptual, correspondente à estrutura linguística do dêitico, e um espaço de input experiencial, referente a configurações gestuais específicas. A integração desses espaços permite que o falante selecione trechos de seu discurso para colocar em proeminência.
\end{abstract}

Palavras-chave: dêixis; Integração Experiencial; gestos.

ABSTRACT: This paper focuses on the spatial deictics 'aqui' (here) and 'lá' (there) in Brazilian Portuguese political discourse, using videotaped data. Drawing on the Cognitive Linguistics framework, the analysis conjugates Mental Spaces Theory and Cognitive Grammar, relying on the notion of Conceptual Integration (FAUCONNIER \& TURNER, 2002), and the related notion of Experiential Integration (AUCHLIN, 2013), as well as the operation of construal, and the related concept of focalization based on foreground/background distinctions (LANGACKER, 1991, 2008, 2013). For the characterization of emergent structure in the blended space, we investigate the relations between specific deictic uses of 'aqui' (here) and 'lá' (there) and associated gestural configurations The results suggest that discursive uses of 'aqui' and 'lá' emerge from the integration of a conceptual input space, which contains the deictic' linguistic structure, and an experiential input space, containing specific gesture configurations. The integration of these input spaces allows the speaker to select discourse pieces s/he wishes to make prominent.

Keywords: deixis; Experiential Integration; gestures.

\section{INTRODUÇÃO}

Este trabalho enfoca o papel dos gestos na construção de significados dêiticos, a partir da análise de uma sessão legislativa da Câmara dos Deputados

\footnotetext{
* Universidade Estadual do Sudoeste da Bahia, Bahia (BA), Brasil. mairavelar@uesb.edu.br

${ }^{* *}$ Universidade Federal do Rio de Janeiro, Rio de Janeiro (RJ), Brasil. lilianferrari@uol.com.br
} 
proferida pelo pastor Silas Malafaia, gravada em vídeo, intitulada "Sessão solene em homenagem ao Dia Nacional de Valorização da Família”. Em especial, busca-se analisar usos do dêitico 'aqui', normalmente indicador da localização do falante. Tomando como ponto de partida a noção de Integração Conceptual (FAUCONNIER \& TURNER, 2002), o principal argumento do trabalho é que os dados analisados evidenciam um tipo específico de integração: a Integração Experiencial (AUCHLIN, 2013), que envolve domínios de naturezas distintas (experiencial e conceptual). Mais especificamente, propomos que usos discursivos do dêitico 'aqui' resultam da mesclagem entre estrutura linguística e gestos que acompanham a produção verbal do dêitico, refletindo a estrutura emergente derivada desse processo. Em particular, pode-se considerar que esse processo de integração promove a operação cognitiva de Construal (LANGACKER 1991, 2008, 2013), que reflete um dos inúmeros modos de conceptualizar e retratar uma determinada situação. Uma das dimensões do Construal consiste na a operação de Focalização, que permite o tratamento de partes específicas do discurso como Figura (Foreground).

O trabalho está organizado em cinco seções principais. A seção 1 estabelece o embasamento teórico para a análise dos gestos, enfocando suas articulações com o fenômeno da dêixis. Na seção 2, os principais postulados da Teoria da Integração Conceptual são apresentados (FAUCONNIER \& TURNER, 2002; HUTCHINS, 2005), com o objetivo de fundamentar o conceito de Integração Experiencial (AUCHLIN, 2013; MIRANDA, 2013), detalhado na seção 3.1. A seção 3 apresenta as operações cognitivas de Construal e Focalização (LANGACKER, 1991, 2008, 2013), que integram a análise do dêitico 'aqui' em termos de Integração Experiencial. A metodologia é apresentada na seção 4 e a análise propriamente dita, na seção 5 .

\section{GESTOS E DÊIXIS}

Do ponto de vista linguístico, os dêiticos, enquanto categoria de signos, só existem na realidade enunciativa, uma vez que só conseguimos estabelecer um referente para as expressões dêiticas na situação de enunciação em que são utilizadas. Nos termos de Levinson (1983), a classificação tradicionalmente estabelecida para a dêixis toma o evento de fala como ponto de referência, destacando os parâmetros de pessoa (exs. eu, você, etc.), tempo (exs. hoje, agora, etc.), lugar (exs. aqui, lá, etc.), social (exs. distinção você/o(a) senhor(a)) e discurso (exs. a seguir, no parágrafo anterior, etc.). Entretanto, conforme ressalta Marmaridou (2000), uma visão experiencial e cognitivista da dêixis requer que a classificação tradicional dos dêiticos seja revista. Segundo a autora, que ao se tratar as categorias dêiticas como desvinculadas e independentes entre si, perdem-se generalizações importantes: por exemplo, há claramente uma relação metafórica entre os dêiticos locativos e temporais, de um lado, e discursivos, de outro. Isso porque os textos orais e escritos exibem aspectos espaciais e temporais, motivando 
a expressão da dêixis discursiva em termos de expressões de local e tempo, como ilustra o exemplo a seguir:

(1) $A i$ vão algumas sugestões. (uso locativo/discursivo)

No exemplo (1), o dêitico locativo 'aí', que expressa originalmente o contraste próximo/distante no espaço, adquire status temporal (referente ao desdobramento do texto) e, a partir daí, caracteriza o que vem a seguir no discurso.

Em contextos multimodais, as expressões dêiticas são frequentemente associadas aos gestos de apontar, uma vez que, em última análise, essas são as "ações não-linguísticas" responsáveis pelo estabelecimento da inter-relação referencial entre o enunciado e as circunstâncias espaço-temporais de sua ocorrência.

Segundo Kendon (2004), os gestos de apontar possuem um padrão comum de movimento, que consiste numa trajetória em linha reta, realizado numa direção específica e direcionado a um alvo específico (KENDON, 2004, p. 200). Para Kendon (2004), as combinações gestuais que contêm o dedo indicador estendido ${ }^{1}$ são frequentemente associadas aos dêiticos espaciais, como é o caso dos dêiticos "aqui" e "lá", objetos elegidos para análise neste trabalho.

Do ponto de vista referencial, os gestos de apontar podem se referir tanto ao espaço físico imediato partilhado pelos interlocutores, e, consequentemente, a um objeto concreto presente no ambiente, como também à estruturação de ideias do falante. Haveria, então, uma utilização dêitica referente à localização do espaço físico. Em contrapartida, haveria também uma utilização dêitica abstrata (MC NEILL; CASSEL; LEVY, 1993), correspondente à localização metafórica de pessoas, objetos ou ideias, que corresponderia à metáfora conceptual "IDEIAS SÃO Овлетоз".

A utilização dêitica metafórica também pode estar relacionada à marcação temporal, que corresponderia à metáfora conceptual "IDEIAS SÃo OBJETOS". Essa segunda utilização metafórica será melhor descrita na seção de metodologia. Segundo Mc Neill e colaboradores (1993), o ato de apontar para um espaço fisicamente vazio, cria, na verdade, um referente orientado espacialmente no contexto discursivo.

\section{A TEORIA DA INTEGRAÇÃO CONCEPTUAL}

A Teoria da Integração Conceptual, inicialmente proposta por Fauconnier \& Turner (2002), visa a explicitar o que acontece do ponto de vista cognitivo quando processamos certos enunciados. Ressaltando o papel fundamental da operação

${ }^{1}$ Kendon distingue entre duas classes de gestos de apontar: gestos de apontar com o dedo indicador e gestos de apontar com a mão aberta. Para maiores detalhes sobre essa distinção, consultar nosso artigo (AVELAR, 2016). 
de integração (ou mesclagem) conceptual na construção do sentido, afirmam os autores (FAUCONNIER \& TURNER, 2003, p.57, tradução nossa):

A integração conceptual é uma operação mental básica que leva a novos significados, a insights globais, e a compressões conceituais, que são úteis para a memória e a para manipulação de arranjos de significado que, na ausência dessa operação, se mostrariam difusos. ${ }^{2}$

A integração conceptual está em conformidade com um conjunto de princípios constitutivos (TURNER, 2007, p. 378): (i) um mapeamento interespacial parcial, que liga algumas contrapartes nos espaços mentais de entrada (input); (ii) um espaço mental genérico que é projetado em cada um dos espaços de input, e contém o que esses espaços têm em comum; (iii) um quarto espaço mental, o espaço de integração ou espaço-mescla; (iv) uma projeção seletiva dos inputs para a mescla. Com relação a esse último princípio, é importante ressaltar que nem todos os elementos e relações dos espaços de input são projetados no espaço-mescla, mas a composição dos elementos e relações projetados permite o desenvolvimento dinâmico de uma estrutura emergente, em que são criados significados novos.

Um exemplo bastante conhecido de integração é o denominado 'Regata', retirado de um relato apresentado por uma revista de navegação sobre a viagem do catamarã Great American II (FAUCONNIER \& TURNER, 2002, p. 63, tradução nossa):

Como relatamos à imprensa, Rich Wilson e Bill Biewenga estavam apenas mantendo uma vantagem de 4,5 dias em relação ao fantasma da caravela (clipper) Northern Light, cujo recorde de viagem de São Francisco a Boston estão tentando bater. Em 1853, a caravela fez o percurso em 76 dias e 8 horas. $^{3}$

O relato destaca dois eventos distintos: a viagem da caravela Northern Light, em 1853, e a viagem do catamarã Great America II, em 1993, percorrendo o mesmo trajeto. Os dois eventos distintos correspondem a dois espaços de input, que refletem aspectos salientes de cada evento (viagem, pontos de partida e chegada, período de tempo, etc.), e compartilham o mesmo frame esquemático de 'barco fazendo uma viagem oceânica de São Francisco a Boston'. Na citação da revista, as duas realizações são integradas em um único evento: uma "corrida" entre o catamarã e o "fantasma" da caravela. A integração conceptual consiste na correspondência parcial entre os espaços de input (o da caravela e o do catamarã), e elementos seletivamente projetados, a partir desses dois espaços, para o espaçomescla:

\footnotetext{
${ }^{2}$ Conceptual blending is a mental operation that leads to new meaning, global insights, and conceptual compressions useful for memory and manipulation of otherwise diffuse ranges of meaning.

${ }^{3}$ As we went to press Rich Wilson e Bill Biewenga were barely maintaining a 4.5 days lead over the ghost of the [clipper] Northern Light, whose record run from San Francisco to Boston he was trying to beat. In 1853, the clipper made the passage in 76 days and 8 hours.
} 


\section{Figura 1: Esquema da Integração Conceptual da corrida de barco}

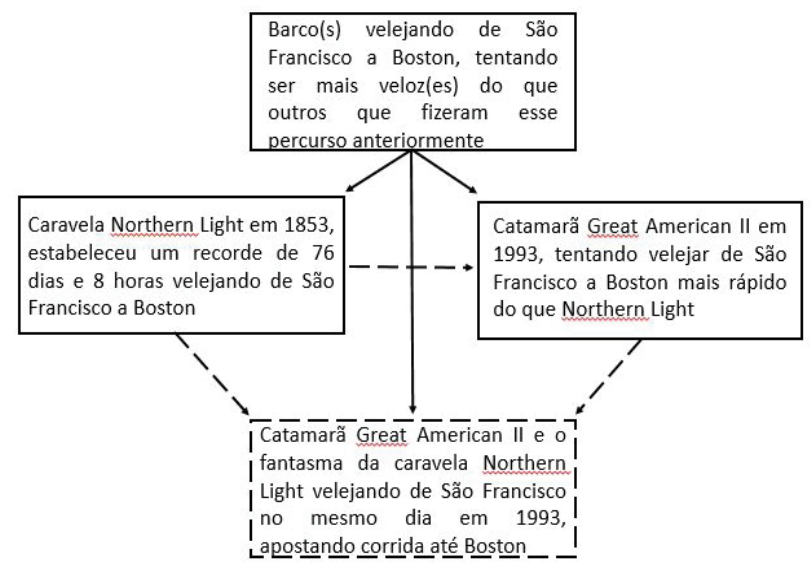

Fonte: Adaptado de Tuggy, 2007, p. 10

Como o exemplo ilustra, um dos benefícios centrais da Integração Conceptual é sua capacidade de comprimir redes difusas de eventos para um nível cognitivamente mais compacto (insight global), e passível de entendimento em 'escala humana'; relações conceituais, tais como 'tempo', 'espaço', 'causa-efeito', 'identidade' e 'mudança' são relações vitais, que podem sofrer compressões maciças por meio da mescla. Assim, no exemplo, a compressão de dois eventos afastados no tempo e no espaço (as viagens das embarcações em épocas distintas) no espaço-mescla, cria a estrutura emergente de 'Regata', em que se tem uma competição. Na mescla (e apenas na mescla), a caravela e o catamarã participam de uma corrida, que é vencida por esse último, permitindo inferências quanto à sua maior eficiência em termos de velocidade.

As âncoras materiais constituem importantes recursos na projeção das mesclas, sobretudo quando se levam em conta dimensões como a gestual e a prosódica, que podem ser consideradas como recursos materiais que fazem parte da elaboração de sentido nas interações. Um dos exemplos discutidos por Fauconnier \& Turner (2002, p. 2011) diz respeito à questão da fala e escrita como âncoras materiais para as mesclas. Segundo os autores, o fato de a escrita ser composta por palavras deriva do espaço da fala. Por exemplo, é possível relacionar categorias escritas como boy, boy, Boy, boy, a categorias sonoras que representam diferentes maneiras de pronunciar a palavra inglesa "boy" (garoto): com sotaque australiano, britânico, com um sussurro etc. Sendo assim, essas palavras/marcas constituem um espaço de input (escrita) e as diferentes maneiras de pronúncia constituem outro (fala). A mescla é, então, formada pela fusão das marcas escritas com a fala.

Como destacado por Hutchins (2005), a associação entre a estrutura material e a estrutura conceptual constitui uma estratégia cognitiva relevante, que merece ser melhor explorada. Por exemplo, numa prática sociocultural como um conjunto de pessoas dispostas em linha reta, uma atrás da outra, fazendo fila para 
comprar ingressos para uma peça teatral, os participantes utilizam o corpo, bem como a localização espacial do corpo, para representarem a ordem de chegada e atendimento dos clientes. Dessa forma, a integração da estrutura física da linha com um trajeto direcional faz com que a linha reta seja interpretada como uma fila. A integração proposta pode ser visualizada a seguir:

\section{Figura 2: Ilustração das âncoras materiais na Integração Conceptual}

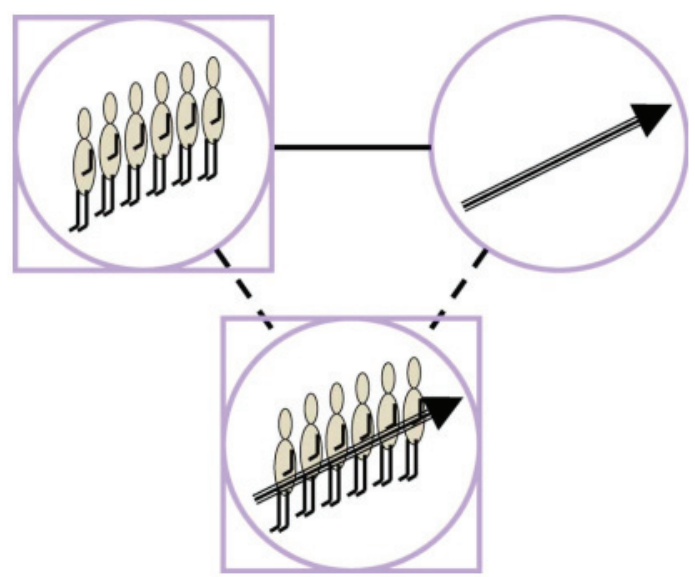

Fonte: Hutchins, 2005, p. 1560

A partir da análise do exemplo, é possível desfazer a ideia de que os espaços de input seriam estruturas mentais conceptuais, apenas: entidades físicas - e não apenas representações mentais dessas entidades - funcionam como espaços de entrada das integrações conceptuais. Isso demonstra que a Integração Conceptual pode derivar da projeção perceptual seletiva de elementos advindos de uma entrada material com a projeção conceptual seletiva de elementos advindos de um espaço conceptual.

Uma vez que a estrutura material é abordada como sendo constitutiva de alguns processos de Integração, não seria o caso de se fazer uma reflexão sobre a própria natureza da Integração realizada? Essa reflexão - e o consequente questionamento da natureza puramente conceptual da integração - , bem como a incorporação de âncoras materiais de maneira mais sistemática, serão abordadas na próxima seção.

\subsection{Integração experiencial}

Nos termos de Auchlin (2013), a Integração Experiencial (IE) é a integração da representação conceptual abstrata e da experienciação sensório-motora das propriedades materiais dos enunciados. Nesse sentido, trata-se de um tipo específico de integração, em que são mesclados dois espaços de input substancialmente distintos, correspondentes ao nível da percepção e da conceptualização. O primeiro 
diz respeito à experiência do "aqui-e-agora" da enunciação e suas propriedades materiais, tal como construídos do ponto de vista perceptivo; o segundo é a elaboração linguística e conceptual.

Como podemos perceber, a Integração Experiencial também constitui um caso de ancoragem material, tal como proposto por Hutchins (2005). No caso da IE, o significado das palavras e enunciados - ou seja, daquilo que é dito - está ligado à dimensão de como percebemos esses enunciados, sobretudo levando-se em consideração questões como naturalidade, escala humana, etc. Por exemplo, um enunciado pronunciado por seres humanos é diferente de um enunciado pronunciado por máquinas. Essa integração entre o que é dito e como é dito diz respeito ao nível emergente de sentido.

Com base na noção de IE, Miranda (2013) analisou discursos de segundo turno às eleições presidenciais de 2010, levando em conta não apenas a dimensão relacionada à estrutura linguística propriamente dita, mas também as dimensões prosódicas e gestuais. O trecho a seguir reproduz uma intervenção da então candidata Dilma Rousseff, dirigida ao também candidato José Serra:

O senhor não tem coragem de assumir a sua posição e fica falando que não se influencia pelos outros.

$\mathrm{Na}$ frase "e fica falando que não se influencia pelos outros", Dilma reporta um comentário anterior de Serra ("Eu não sou influenciado pela posição política alheia"), mas corporifica sua discordância em relação a ele, tanto por meio de gestos (tombando as mãos de um lado para outro, repetidas vezes), quanto por meio da prosódia (realizando uma pausa após a palavra "influencia" para enfatizála). O gesto repetido pode ser considerado uma metáfora de base corporal, tal como "COVARDIA É TOMBAR DE UM LADO PARA O OUTRO", tendo em vista que na frase anterior Dilma havia apontado a falta de coragem de Serra. A correlação entre as dimensões prosódica, gestual e linguística na dimensão experiencial pode ser visualizada no esquema abaixo:

\section{Figura 3: Integração Experiencial da amostra relativa à fala de Dilma}

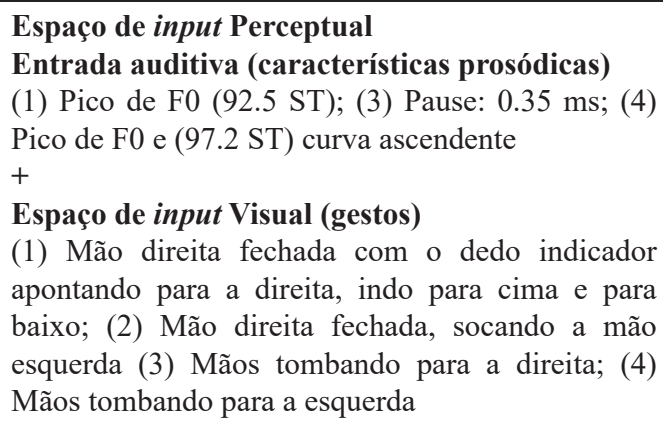

Espaço de input Linguístico

(1) O senhor não tem coragem

(2) de assumir a sua posição

(3) e que fica falando que num se

(4) influencia pelos outros. 


\section{Espaço-mescla}

(1) Acusação do interlocutor

(2) Ênfase na falta de posicionamento do interlocutor

$(3,4)$ Discordância com a informação veiculada

pelo interlocutor

Fonte: Adaptado de Miranda, 2013

O diagrama representa a Integração Experiencial entre o conteúdo perceptivo, incluindo as dimensões de gesto e prosódia, e o conteúdo linguístico, que diz respeito à estrutura linguística (forma e significado). Conjugando aspectos linguísticos e experienciais, associados aos gestos, nosso objetivo é discutir a estrutura emergente que se estabelece a partir da Integração Experiencial que caracteriza esses usos. Na seção de análise, a seguir, buscamos lançar luz sobre a construção de significados dêiticos, elegendo como objeto de estudo os usos dos dêiticos locativos 'aqui' e 'lá'.

\section{CONSTRUAL E FOCALIZAÇÃO}

Para detalhar a construção do significado que emerge do processo de Integração Experiencial, recorremos à noção de construal, que constitui um dos eixos fundamentais da descrição semântica sob a perspectiva cognitivista (LANGACKER, 1991, 2008, 2013). Com base na premissa de que o significado de uma expressão não inclui apenas o conteúdo conceptual evocado, mas também o modo pelo qual esse conteúdo é 'construído', o fenômeno de construal pode ser caracterizado a partir de uma metáfora visual. Assim como a percepção de uma situação depende de um conjunto de parâmetros associados ao observador - grau de proximidade com que examina a cena, a parte da cena em que decide fixar o olhar, os elementos aos quais presta mais atenção e o local de onde a observação é feita -, a construção do significado pode ser tratada a partir de correlatos conceptuais desses parâmetros de percepção. Na Gramática Cognitiva langackeriana, esses correlatos são denominados Especificidade, Perspectiva, Proeminência e Focalização, brevemente definidos a seguir.

A Especificidade diz respeito ao nível de precisão com que se caracteriza uma situação/objeto. Por exemplo, uma entidade material pode ser referida em termos esquemáticos como 'coisa' ou, em termos cada vez mais específicos, como 'objeto', 'lápis', 'lápis de cor', etc. A noção de Perspectiva representa a relação entre o 'observador' (conceptualizador) e a 'cena observada' (cena conceptualizada), caracterizando o arranjo perceptual que se estabelece a partir de um determinado 'ponto de observação' (ou 'ponto de vista'). Enquanto o arranjo perceptual estabelecido normalmente nas interações conversacionais assume implicitamente que os interlocutores estão reunidos em um local fixo, a partir do qual descrevem o mundo que os cerca (ex. A criança viu o avião), há desvios possíveis desse arranjo, envolvendo a posição relativa dos observadores. Por exemplo, a sentença 
"As árvores estão passando a $100 \mathrm{~km}$ por hora" pode ser produzida pelo viajante de um trem; o movimento do veículo engendra no observador uma percepção de mudança que, embora virtual, é descrita como se fosse real. O conceito de Proeminência, por sua vez, está relacionado a saliência cognitiva, englobando uma série de dimensões, que se refletem na organização categorial (ex. o protótipo é mais proeminente do que os demais membros da categoria), nas assimetrias entre oposições em que o primeiro elemento do par é mais proeminente (ex. concreto vs. abstrato, real vs. imaginário, explícito vs. implícito, etc.), e na focalização. Essa última dimensão envolve as relações figura/fundo (foreground/background), de modo que o que é selecionado como figura se torna proeminente em relação ao que não foi selecionado, mas mantido como fundo.

A Focalização é especialmente relevante para o presente trabalho, na medida em que também permite captar assimetrias de proeminência em nível discursivo. Estudos funcionalistas clássicos, como o de Hopper \& Thompson (1980), demonstram que o 'fio condutor' das narrativas - a série de eventos sequenciais - se destaca como figura em relação ao fundo, que é constituído por descrições estáticas das personagens e da situação. De maior relevância para a análise desenvolvida no presente trabalho, incluem-se casos em que é possível distinguir o conteúdo que o falante destaca como importante para o foco da discussão dos comentários subsidiários. Conforme ilustrado por Langacker (2013) e adaptado para o português no exemplo a seguir, estratégias fonológicas podem estar a serviço dessa distinção (a marca em itálico e a fonte menor indicam que a expressão é não acentuada e produzida tom mais baixo):

(3) Eu acho que ele será candidato.

Embora a cláusula principal em (3) seja figura em termos estruturais, é alçada à condição de fundo, em função dos recursos fonológicos mencionados, evidenciando que a sintaxe da fala se comporta de maneira muito diferente da sintaxe da escrita.

No que se refere à análise desenvolvida neste trabalho, a proposta é que a ocorrência do dêitico 'aqui', associada a gestos específicos, contribui para o estabelecimento de estratégias de focalização, permitindo sinalizar trechos mais relevantes do discurso, a partir do ponto de vista do falante. Antes de procedermos à análise, entretanto, apresentamos as bases metodológicas da pesquisa na seção a seguir.

\section{METODOLOGIA}

Tendo em vista que o objetivo principal do trabalho é identificar e caracterizar os usos dos dêiticos 'aqui' e 'lá' em debates político-eleitorais, em termos verbogestuais, a pesquisa utiliza dados retirados do vídeo de uma sessão legislativa, com 11 minutos de duração, em que o consultor legislativo Silas Malafaia, líder religioso evangélico de bastante proeminência no Congresso Nacional, foi o 
responsável pela "sessão solene em honra ao dia da família". Ele discursou na tribuna da Câmara dos Deputados para a plenária e também para os telespectadores da TV Câmara. O mote da fala do pastor foi a defesa da família nuclear: "homem, mulher e sua prole", tendo realizado amplo uso de recursos gestuais e também de recursos dêiticos, como ilustraremos na seção de análise.

A fim de ilustrar o funcionamento dos dêiticos "aqui" e "lá" num contexto multimodal, selecionamos quatro amostras representativas da ocorrência dos dêiticos, levando em consideração não apenas a dimensão verbal, mas também a dimensão gestual. Do ponto de vista operacional, gestos constituem "movimentos distintos de esforço identificável das mãos e antebraços, ou seja, o golpe (stroke) dos gestos" (CIENKI, 2005, p. 425). Sendo assim, fotografamos o golpe gestual correspondente à representação icônica dos dêiticos "aqui" e "lá", prototipicamente definidas como "apontar para baixo" e "apontar para fora", respectivamente.

A partir de uma trilha de análise criada no ELAN (SLOETDJES; WITEENBURGH, 2008), foram analisados os seguintes parâmetros:

a) Conteúdo verbal, em que apresentamos a transcrição ortográfica dos trechos selecionados para análise. Os trechos destacados em negrito correspondem à porção do sintagma em que ocorre o golpe gestual.

b) Direção do movimento, em que descrevemos se o golpe foi feito para dentro, para fora, para cima, para baixo, para a direita, para a esquerda. Os parâmetros de direção foram escolhidos com base em McNeill (1992), considerando o nível básico de movimento que o locutor desempenha ocupando um espaço em 3D.

c) Amplitude do movimento, em que descrevemos se foi utilizada uma articulação (o dedo), duas articulações (o dedo e o antebraço) ou três articulações (o dedo, o antebraço e o braço).

d) Qualidade do movimento, em que descrevemos se o movimento realizado foi preciso ou impreciso. ${ }^{4} \mathrm{O}$ primeiro movimento é realizado com os membros tensos, enquanto o segundo é realizado com os membros mais relaxados.

A análise dos dados baseou-se nas seguintes hipóteses: (i) Os dêiticos locativos 'aqui' e 'lá' apresentam usos semântico-pragmáticos metaforizados no discurso político; (ii) Os gestos que acompanham esses usos promovem uma integração experiencial cuja estrutura emergente focaliza partes específicas do discurso.

A hipótese (i) refere-se a usos discursivos, e não propriamente locativos, dos dêiticos 'aqui' e 'lá', na esteira da visão experiencialista proposta por Marmaridou (2000).

Quanto à hipótese (ii), a ideia é que a integração entre as estruturas dêiticas 'aqui'/'lá e gestos resulta em uma estrutura emergente com construal específico, em termos de focalização. Essa estrutura permite que o falante sinalize o que é figura, em contraste com o que é fundo no discurso, conforme análise desenvolvida na seção a seguir.

${ }^{4}$ Em inglês, utiliza-se os termos sharpness (nitidez) e smoothness (suavidade). 
A descrição dos quatro parâmetros gestuais escolhidos permite que analisemos se os gestos analisados são realizados de maneira mais ou menos ostensiva, de modo a focalizar mais ou menos a atenção do interlocutor para a referência evocada, tanto no gesto realizado, quanto na fala que o acompanha (cf. hipótese 2, descrita anteriormente).

\section{ANÁLISE}

A análise dos dados permitiu a identificação de dois fenômenos interrelacionados, que evidenciam a emergência de significados discursivos, e não puramente locativos, no uso dos dêiticos. No primeiro caso, há uma incongruência entre o locativo selecionado e o gesto realizado; no segundo, apesar de haver congruência entre gesto e dêitico, trata-se de uma congruência aparente. Nas seções subsequentes, os dois casos serão apresentados e discutidos.

\subsection{Incongruência entre dêiticos e gestos}

Os usos prototípicos dos dêiticos 'aqui' e 'lá' prenunciem gestos de apontar para baixo e apontar para fora, respectivamente, como ilustrado a seguir:

\section{Figura 4: Gesto de apontar para baixo}

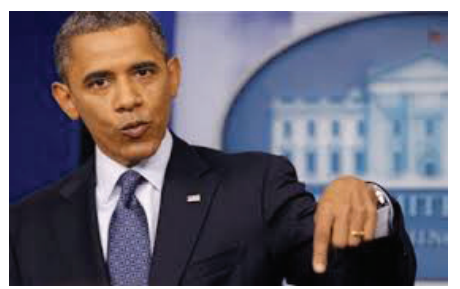

Dedo indicador esticado, demais dedos dobrados, palma da mão voltada para dentro, pulso dobrado, cotovelo na vertical ou na diagonal, antebraço a cerca de 45 graus, movimento descendente.

Fonte: Banco de imagens das autoras

Figura 5: Gestos de apontar para fora

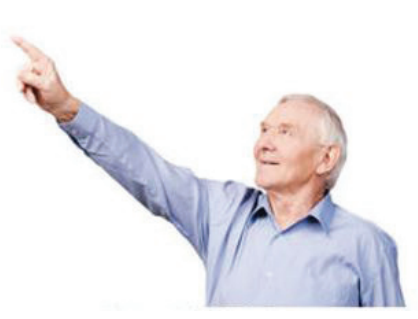

Dedo indicador esticado, demais dedos dobrados, palma da mão voltada para fora, pulso, antebraço e braços esticados, movimento ascendente ou reto, para fora do corpo.

\section{Fonte: Banco de imagens das autoras}

${ }^{5}$ Para realizarmos a descrição gestual proposta, ancoramo-nos nos parâmentros descritos por Bressem e colaboradoras (2013): forma das mãos (que inclui os dedos), orientação das palmas e direção do movimento. 


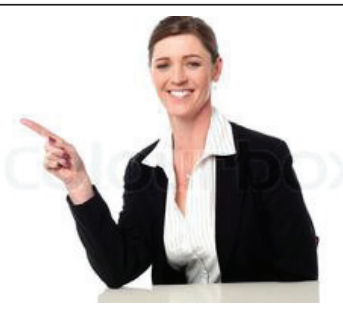

Dedo indicador esticado, demais dedos dobrados, palma da mão voltada para fora, pulso levemente tombado, cotovelo na vertical ou, antebraço a cerca de 75 graus, movimento para fora do corpo.

Entretanto, foram observados usos incongruentes dos dêiticos em questão, que passamos a descrever a partir da análise de duas amostras pertencentes ao discurso de Malafaia, retiradas do seguinte trecho:

Rapaz, esses caras querem bagunçar, querem destruir a família. A família tem/ É lá, é lá na família que o ser humano aprende limite. É lá na família que o ser humano aprende respeito. É lá na família que o indivíduo recebe a punição, para ele não receber a punição aqui fora.

Observemos a primeira amostra de análise:

\section{Amostra 1}

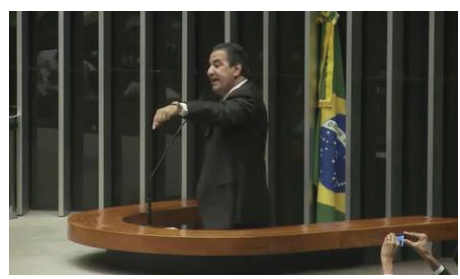

É lá na família que o ser humano aprende respeito.

Mão direita apontando repetidamente para baixo.

Na primeira amostra de análise, o locutor enuncia o dêitico "lá" ("É lá na família que...") Entretanto, realiza o gesto de apontar para baixo, prototípico do dêitico "aqui", o que caracteriza uma incongruência entre o dêitico enunciado e o gesto realizado.

Consideremos, a seguir, a segunda amostra:

Amostra 2

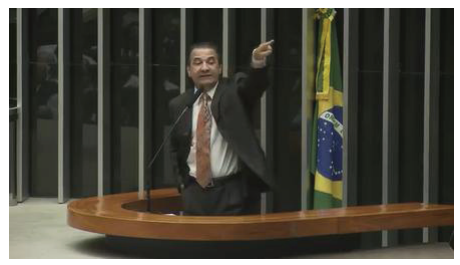

Pra ele não receber a punição aqui fora

Mão direita apontando para fora.

Na segunda amostra, o locutor enuncia o dêitico "aqui ("Pra ele não receber a punição aqui fora"); porém, utiliza o gesto de apontar para fora, que marca 
prototipicamente o dêitico "lá", caracterizando, mais uma vez, uma incongruência entre o dêitico enunciado e o gesto realizado.

Do ponto de vista multimodal, haveria, em ambas as amostras, uma incongruência entre o locativo enunciado e o gesto. Na verdade, essa incongruência é desfeita quando observamos que o dêitico não funciona como locativo: ao invés disso, é utilizado para marcar metaforicamente o espaço discursivo. E é justamente a incongruência entre dêiticos e gestos que opera a integração experiencial que permite não apenas a emergência de significados discursivos (metaforizados), mas também a focalização de conteúdos relevantes do ponto de vista do falante. Portanto, essas duas ocorrências sustentam nossas hipóteses de trabalho.

\subsection{Congruência aparente entre dêiticos e gestos}

Diferentemente do que foi apresentado na seção anterior, os usos a serem discutidos nesta seção parecem puramente icônicos, na medida em que há congruência entre o significado dos dêiticos e o tipo de gesto realizado. Entretanto, outras pistas contextuais sugerem que essa congruência é apenas aparente.

$\mathrm{Na}$ terceira e na quarta amostras de análise, há uma correspondência entre o uso do "aqui", enunciado na fala, e o gesto de apontar para baixo, que marca prototipicamente a ocorrência desse mesmo dêitico nos gestos. Observemos esses usos, retirados do trecho final do discurso de Malafaia:

Espero que essa Casa aqui, os senhores aqui defendam a família nuclear, base de uma sociedade sadia. (...) Eu quero deixar uma declaração profética, em nome de Jesus: todo tipo de lei que venha destruir a família, aqui nessa casa, caia por terra. Deus abençoe a todos.

Amostra 3

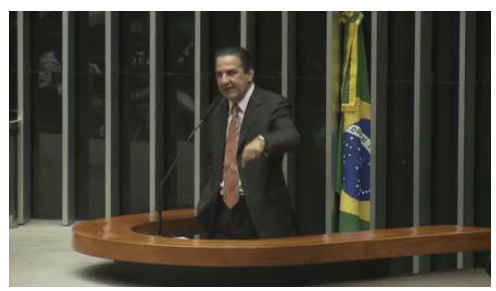

Que essa casa (1) aqui (2), os senhores (1) aqui (2)

Mão direita apontando para baixo.

\section{Amostra 4}

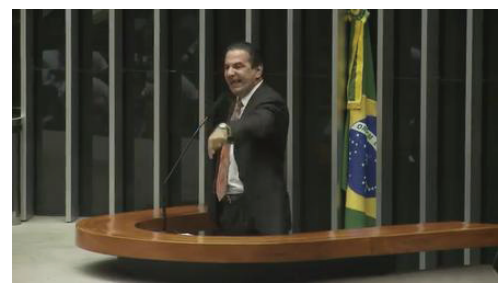

Aqui (1) nessa casa (2)

Mão direita apontando para baixo. 
Embora se verifique uma congruência entre dêiticos e gestos, deve-se levar em conta que a própria ocorrência do dêitico "aqui", nesses contextos, parece ser redundante, já que outro dêitico locativo já faz parte do sintagma nominal "essa casa" Além disso, a repetição do gesto, bem como o movimento repetitivo ao realizar o golpe gestual que, por sua vez, co-ocorre com a marcação de ênfase prosódica, demonstram que a marcação dêitica multimodal funciona mais como sinalizadora de tópico discursivo do que como marcadora de espaço físico - $\mathrm{c}$. f. detalhado na discussão dos resultados realizada a seguir. Trata-se, portanto, de uma congruência aparente, já que o significado global emerge da integração experiencial entre item linguístico, gesto, fatores contextuais e prosódia.

\subsection{Discussão e síntese dos resultados}

Com relação à análise apresentada, o primeiro ponto que merece destaque é o fato de que os usos dêiticos discutidos envolvem ocorrências em que a omissão do dêitico seria plenamente aceitável. O quadro, a seguir, apresenta os trechos relevantes e sua contraparte sem os dêiticos:

\section{Quadro 1: Amostras efetivas e contrapartes sem dêiticos}

AMOSTRAS 1 e 2

É lá na família que o indivíduo recebe a punição, para ele não receber a punição aqui fora.

AMOSTRAS 1 e 2 (SEM DÊITICOS)

É na família que o indivíduo recebe a punição, para ele não receber a punição fora.

AMOSTRAS 3 e 4

Eu quero deixar uma declaração profética, em nome de Jesus: todo tipo de lei que venha destruir a família, aqui nessa casa, caia por terra. Espero que essa Casa aqui, os senhores aqui defendam a família nuclear, base de uma sociedade sadia. (...)

AMOSTRAS 3 e 4 (SEM DÊITICOS)

Eu quero deixar uma declaração profética, em nome de Jesus: todo tipo de lei que venha destruir a família, nessa casa, caia por terra. Espero que essa Casa, os senhores defendam a família nuclear, base de uma sociedade sadia. (...)

Fonte: Elaborado pelas autoras

A possibilidade apontada no Quadro 1 parece configurar evidência adicional de que os dêiticos analisados se caracterizam, de fato, como marcadores de

${ }^{6}$ Embora, tradicionalmente, os demonstrativos 'este' e 'esse' sejam descritos em termos da oposição 'próximo ao falante' e 'próximo ao ouvinte', a oposição não parece vigorar no português brasileiro coloquial, em que 'esse’ passou a ser usado nas duas situações. 
ênfase discursiva. Além disso, como é possível observar no quadro-síntese dos resultados, em todas as amostras de análise, o gesto aparece como marcador de ênfase, pois é realizado de maneira precisa e utilizando-se as três articulações:

Quadro 2: Síntese dos resultados

\begin{tabular}{|l|l|l|l|l|}
\hline Amostra & Conteúdo verbal & $\begin{array}{l}\text { Direção do } \\
\text { movimento }\end{array}$ & $\begin{array}{l}\text { Amplitude do } \\
\text { movimento }\end{array}$ & $\begin{array}{l}\text { Qualidade } \\
\text { do } \\
\text { movimento }\end{array}$ \\
\hline Amostra 1 & $\begin{array}{l}\text { É lá na família que o } \\
\text { ser humano aprende } \\
\text { respeito. }\end{array}$ & Para baixo & $\begin{array}{l}\text { Três } \\
\text { articulações }\end{array}$ & Preciso \\
\hline Amostra 2 & $\begin{array}{l}\text { Pra ele não receber a } \\
\text { punição aqui fora }\end{array}$ & Para fora & $\begin{array}{l}\text { Três } \\
\text { articulações }\end{array}$ & Preciso \\
\hline Amostra 3 & $\begin{array}{l}\text { Que essa casa (1) } \\
\text { aqui (2) }\end{array}$ & Para baixo & $\begin{array}{l}\text { Três } \\
\text { articulações }\end{array}$ & Preciso \\
\hline Amostra 4 & $\begin{array}{l}\text { Aqui (1) nessa casa } \\
(2)\end{array}$ & Para baixo & $\begin{array}{l}\text { Três } \\
\text { articulações }\end{array}$ & Preciso \\
\hline
\end{tabular}

Fonte: Elaborado pelas autoras

A realização de gestos precisos e ostensivos - ou seja: realizados de maneira a mobilizar a atenção do interlocutor - somada à função dos gestos como marcadores de tópico discursivo e à co-ocorrência deles com marcadores de ênfase prosódica nas duas últimas amostras está de acordo com as nossas hipóteses, de que os dêiticos "aqui" e "lá" apresentam usos discursivos (metaforizados), que resultam da integração experiencial entre a estrutura dêitica e os gestos. Do ponto de vista da integração experiencial, tem-se, nos exemplos analisados, o Espaço de input 1, composto pela dimensão material, relativa aos gestos de apontar para baixo e apontar para fora; e, eventualmente, aos recursos prosódicos utilizados pelo falante. O Espaço de input 2, por sua vez, comporta os dêiticos 'aqui' e 'lá', enunciados em cada uma das amostras analisadas. Assim, as estruturas emergentes - Espaço-mescla - engendram um Construal específico, em termos de focalização, de modo que os conteúdos marcados com os dêiticos multimodais são apresentados pelo falante como pontos mais proeminentes ("figura") de seu discurso.

\section{CONSIDERAÇÕES FINAIS}

Este trabalho enfocou usos dos dêiticos locativos "aqui" e "lá", a partir de dados retirados de vídeo de uma sessão legislativa, que registra o discurso do Pastor Silas Malafaia na Câmara dos Deputados para a plenária e telespectadores da TV Câmara. A análise identificou usos de "aqui" e "lá" que se afastam do significado locativo básico associado aos dêiticos, e assumem caráter discursivo, a partir de mapeamentos metafóricos. Esses usos podem indicar tanto incongruência 
quanto congruência aparente entre elemento dêitico e gestos, ativando processos de integração experiencial que permitem a construção de significados emergentes, a partir da operação cognitiva de Construal, em que os dêiticos colocam em proeminência, através da Focalização de conteúdos discursivos que o falante busca enfatizar.

O estudo aqui apresentado constitui uma aproximação inicial dos fenômenos abordados, contribuindo, por um lado, para o aprofundamento da noção de Integração Experiencial, aplicada pioneiramente por Miranda (2013) para tratar de metáforas multimodais no português brasileiro; por outro lado, o estudo permite a expansão do escopo analítico na descrição dos dêiticos, apontando caminhos instigantes de análise, que podem permitir o refinamento da Teoria da Integração Conceptual, bem como contribuir para a compreensão mais ampla do conhecimento lingúístico em suas relações com o uso.

\section{REFERÊNCIAS BIBLIOGRÁFICAS}

AUCHLIN, A. Prosodic Iconicity and Experiential Blending. In: HANCIL, S. (Ed.) Prosody and Iconicity. Amsterdam: John Benjamins, 2013.

AVELAR, M. O papel dos gestos de apontar na construção da dêixis multimodal: dos usos concretos aos usos abstratos. Revista LinguíStica, v. 1, n. 12, 2016, p.161-176.

BRESSEM, J. et al. A liguistic perspective on the notation of form features in gestures. In: MÜLLER, C. et al (Eds.) Body - Language - Communication: An International Handbook in Multimodality in Human Interaction. Berlin, New York: Mouton de Gruyter. 2013, p. 1079-1099.

CIENKI, A. Image Schemas and Gestures. In: HAMPE, B; GRADY, J. (Eds.). From Perception to Meaning: Image Schemas in Cognitive Linguistics. Berlin, New York: Mouton de Gruyter. 2005, p. 421-442.

FAUCONNIER, G. e TURNER, M. The way we think; conceptual blending and the mind's hidden complexities. New York: Basic Books, 2002.

HOPPER, P e THOMPSON, S. Transitivity in grammar and discourse. Language 56, 1980, 251-299.

HUTCHINS, E. Material anchors for conceptual blending. Journal of Pragmatics 37, 2005, 15551577.

KENDON, A. Gesture: visible action as utterance. Cambridge: Cambridge University Press.

LANGACKER, R. Foundations of Cognitive Grammar (Descriptive Applications), v. II. Stanford: Stanford University Press, 1991.

LANGACKER, R. Cognitive Grammar: a basic introduction. New York: Oxford University Press, 2008

LANGACKER, R. Essentials of Cognitive Grammar. Oxford: Oxford University Press, 2013.

LEVINSON, S. Pragmatics. Cambridge: Cambridge University Press, 1983. 
MARMARIDOU, S. Pragmatic meaning and cognition. Amsterdam/Philadelphia: John Benjamins Publishing Co, 2000.

MC NEILL, D. Hand and Mind: What Gestures Reveal about Thought. Chicago: Chicago University Press, 1992.

MC NEILL, D.; CASSELL, J; LEVY, E.T. Abstract deixis. Semiotica, v. 95, n.1. Berlin: Walter de Gruyter, 1993, p. 5-19.

MIRANDA, M. A. A emergência de metáforas multimodais no discurso político-eleitoral: análise de variáveis verbais, prosódicas e gestuais em debates de segundo turno às eleições presidenciais de 2010. Tese de Doutorado. Programa de Pós-Graduação em Letras, PUC Minas, 2013.

TUGGY, D. Schemacity. In: GEERAERTS, D; CUYCKENS, H. The Oxford Handbook of Cognitive Linguistics. Oxford: Oxford University Press, 2007, p. 82-116.

TURNER, M. Conceptual Integration. In Geeraerts, D. \& Cuyckens, H. (eds.). The Oxford Handbook of Cognitive Linguistics, 2007, 377-393.

SLOETDJES, H., \& WITTENBURGH, P. ELAN. Version 4.8.1, retrievied 20 November 2014 from http://tla.mpi.nl/tools/tla-tools/elan/ by Max Planck Institute for Psycholinguistics, The Language Archive, Nijmegen, The Netherlands, 2008.

Recebido: 14/02/2017

Aceito: 21/03/2017 